\title{
Correction to: Compendium of Surface and Interface Analysis
}

The Surface Science Society of Japan

\section{Correction to:}

The Surface Science Society of Japan (ed.), Compendium

of Surface and Interface Analysis, https://doi.org/10.1007/978-981-10-6156-1

The original version of Chapters 5, 39, 86, 110 and 117 was published with errors in text and in equation. The correction chapters have been now updated with the changes.

The updated versions of these chapters can be found at https://doi.org/10.1007/978-981-10-6156-1_5 https://doi.org/10.1007/978-981-10-6156-1_39 https://doi.org/10.1007/978-981-10-6156-1_86 https://doi.org/10.1007/978-981-10-6156-1_110

https://doi.org/10.1007/978-981-10-6156-1_117 